\title{
High Resolution XRD Studies on Mg, Cr and Nd Doped $\mathrm{LiNbO}_{3}$ Crystals
}

\author{
S. $\operatorname{Kar}^{1}$, H. Ryu ${ }^{2}$ and K.S. Bartwal*,1,2 \\ ${ }^{1}$ Laser Materials Development and Devices Division, Raja Ramanna Centre for Advanced Technology, Indore -452 013, \\ India \\ ${ }^{2}$ Energy Materials Research Centre, Korea Research Institute of Chemical Technology, Daejeon-305-600, South Korea
}

\begin{abstract}
Undoped and doped $\mathrm{LiNbO}_{3}$ single crystals were grown by Czochralski technique. Comparative studies on these undoped, $\mathrm{Cr}$ doped, $\mathrm{Mg}$ doped, $\mathrm{Mg}: \mathrm{Cr}$ codoped and $\mathrm{Mg}: \mathrm{Nd}$ codoped $\mathrm{LiNbO}_{3}$ single crystals were carried out. Phase identification was done using powder XRD technique. The effect of doping and co-doping on crystalline perfection of these crystals was monitored using high resolution x-ray diffraction (HRXRD) technique. The diffraction curves (DCs) were recorded in symmetrical Bragg geometry for (006) diffracting planes using $\mathrm{MoK} \alpha_{1}$ radiation.
\end{abstract}

\section{INTRODUCTION}

Lithium niobate, $\mathrm{LiNbO}_{3}$ is one of the most widely studied functional materials because of its diversified applications in opto-electronics industry $[1,2]$. $\mathrm{LiNbO}_{3}$ crystals are thermodynamically non-stoichiometric and characterized by defect structure. This non-stoichiometry results in high concentration of intrinsic defects and disorder in the crystal. These defect sites can easily incorporate impurities, the external defects, and the necessary charge compensations can be easily balanced by intrinsic defects. The photo refractivity and quality of holographic devices in this material depends on the presence of defect generated during growth as well as deliberately added impurities. Usually transition metal ions are added for these purposes. Lithium niobate doped with transition metal ion $\mathrm{Cu}, \mathrm{Fe}, \mathrm{Mn}, \mathrm{Ce}$ etc., exhibit significant photo refractive properties and is potential material for holographic memories [3]. A serious disadvantage of undoped congruent $\mathrm{LiNbO}_{3}$ crystal is that it usually shows the so called "optical damage" a kind of photo refractive effect, when irradiated with high power laser beam of visible wavelength. This effect limits the stability of undoped $\mathrm{LiNbO}_{3}$ crystal in nonlinear optical applications. Photorefractive phenomena in ferroelectrics materials are related to the incorporation of impurities (extrinsic defects) or presence of structural defects (intrinsic defects), acting as donors and acceptors for charge carriers. The role of defect structure on the electronic and structural characteristics of the crystals is very significant to understand their physical and chemical nature $[4,5]$. The well established band structure approach for variation in optical properties of congruent $\mathrm{LiNbO}_{3}$ is given by Kityk et al. [6, 7].

$\mathrm{LiNbO}_{3}$ doped with various transition metal and rare earth ions is a laser host material, which could be used for tunable self-frequency doubling lasers [8]. One of the most studied dopant in $\mathrm{LiNbO}_{3}$ is $\mathrm{Cr}^{3+}$ ion. Several $\mathrm{Cr}^{3+}$ centers have been detected in $\mathrm{LiNbO}_{3}$ crystals [9]. Their existence depends on several factors as doping level, stoichiometry of the crystal and co-doping with other ions. Especially impor-

*Address correspondence to this author at the Energy Materials Research Centre, Korea Research Institute of Chemical, Technology, Daejeon- 305600, South Korea; Tel: +82-42-860-7376; Fax: +82-42-861-4245; E-mail: bartwalks@yahoo.co.in tant is co-doping with $\mathrm{Mg}$ or $\mathrm{Zn}$ at a level above $4.5 \mathrm{~mol} \%$, which inhibits photorefractive properties of the material. Another potential application of $\mathrm{LiNbO}_{3}$ is in $\mathrm{Nd}^{3+}$ based compact diode-pumped self-frequency doubled lasers that emit green radiation, useful for applications in optical data storage, and excitation sources to replace ion gas lasers and pumping of parametric oscillators and amplifiers [10]. The understanding of the optical properties of $\mathrm{Nd}^{3+}$ ions in lithium niobate crystals has gained considerable attention after demonstration of efficient laser oscillation for the $\mathrm{Nd}: \mathrm{Mg}: \mathrm{LiNbO}_{3}$ system [11]. When $\mathrm{LiNbO}_{3}$ devices are used at high laser intensity, their performance is severely limited by the optical damage effect, which induces birefringence change and deforms the laser beams. Some damage resistant impurities have been reported, such as divalent $\left(\mathrm{Mg}^{2+}[12]\right.$, $\left.\mathrm{Zn}^{2+}[13]\right)$ and trivalent $\left(\mathrm{In}^{3+}[14]\right.$, and $\left.\mathrm{Sc}^{3+}[15]\right)$ impurities, which lead to a strong decrease of the photo damage in $\mathrm{LiNbO}_{3}$ and have been receiving a lot of interest. In this paper we have studied the effect of doping and co-doping on lithium niobate crystal lattice using powder x-ray diffraction (XRD) and high resolution $\mathrm{X}$-ray diffraction (HRXRD).

\section{EXPERIMENTAL DETAILS}

The single crystals of $\mathrm{LiNbO}_{3}$ were grown by Czochralski technique. $\mathrm{LiNbO}_{3}$ is an incongruently melting material. The congruently melting point is $1240 \pm 5{ }^{\circ} \mathrm{C}$, and it is at the composition $48.6 \mathrm{~mol} \%$ of $\mathrm{Li}_{2} \mathrm{O}$. Usually, $\mathrm{LiNbO}_{3}$ crystals are grown from the melt with a composition 51.4/48.6 for the molar ratio of $\mathrm{Nb}_{2} \mathrm{O}_{5} / \mathrm{Li}_{2} \mathrm{CO}_{3}$, which is the congruent melt composition. Starting materials of $\mathrm{Nb}_{2} \mathrm{O}_{5}$ and $\mathrm{Li}_{2} \mathrm{CO}_{3}$ with $4 \mathrm{~N}$ purities were weighed according to the composition at the congruent melting point and mixed. Different dopants were added to the charge as per the desired composition. The mixture was ball-milled for 8-10 hours to ensure proper mixing. The ball-milled mixture was kept in a furnace for solidstate reaction at $1000{ }^{\circ} \mathrm{C}$ for 24 hours. This process was repeated to ensure the completion of solid-state reaction. The reacted charge was ground, remixed and $50 \mathrm{~mm}$ diameter pallets were made for crystal growth experiments. These pallets were placed in a $60 \mathrm{~mm}$ diameter and $60 \mathrm{~mm}$ height platinum crucible for crystal growth runs in air atmosphere. The charge was melted using induction-heating system. The melt was homogenized for 1-2 hours at a temperature little above the melting point. A seed crystal in [00.1] orientation 
was inserted into the melt at $1-2{ }^{\circ} \mathrm{C}$ above the melting point. Pulling rate was $12 \mathrm{~mm} / \mathrm{h}$. Specially designed growth chamber was used for growth of crack-free and colorless crystals. Platinum cylinder was used as an after-heater to ensure a controlled post growth cooling of the crystal. The post growth cooling was maintained at a rate $10-15^{\circ} \mathrm{C} / \mathrm{h}$ initially up to $800{ }^{\circ} \mathrm{C}$, and thereafter $20-25^{\circ} \mathrm{C} / \mathrm{h}$ to room temperature [16]. Different undoped and doped crystals were grown successfully. The compositions grown in the present study were undoped $\mathrm{LiNbO}_{3}, 7 \mathrm{~mol} \% \mathrm{Mg}$ doped $\mathrm{LiNbO}_{3}, 7 \mathrm{~mol} \% \mathrm{Mg}$, $0.5 \mathrm{~mol} \% \mathrm{Cr}$ co-doped $\mathrm{LiNbO}_{3}$, and $7 \mathrm{~mol} \% \mathrm{Mg}$ and $1 \mathrm{~mol} \%$ $\mathrm{Nd}$ co-doped $\mathrm{LiNbO}_{3}$. A small portion of grown crystal was crushed properly for powder XRD study. $18 \mathrm{~kW}$ RIGAKU x-ray generator with $\mathrm{Cu} \mathrm{K}_{\alpha}$ wavelength $(1.5418 \AA)$ was used for X-ray diffraction experiments. Powder XRD patterns were taken for different undoped and doped samples. The XRD spectra were compared with the JCPDS data file for congruent $\mathrm{LiNbO}_{3}$ crystal.

In order to monitor the crystalline perfection of these as grown crystals, high-resolution X-ray diffraction (HRXRD) measurements were performed. A multicrystal x-ray diffractometer (MCD) was used for these experiments [17]. A finefocus X-ray tube (Philips, $0.4 \times 8 \mathrm{~mm}$, Mo $2 \mathrm{~kW}$ ) is energized by a well stabilized Philips X-ray generator (Philips PW1743). The white X-ray beam first passes a long collimator (fitted with a special set of slits at one end) and is then diffracted from two plane (111) Si monochromator crystals of Bonse-Hart type. A well collimated Mo $\mathrm{K}_{1}$ beam is isolated and further diffracted from a third plane monochromator crystal of dislocation free $\mathrm{Si}$ in the dispersive symmetrical Bragg geometry $(+,-,-)$ configuration. This arrangement particularly improves the spectral purity of the $K \alpha_{1}$ beam. The well-polished specimen crystal was aligned in the $(+,-,-,+)$ symmetrical Bragg geometry. The rotation given by the main turntable to the specimen around a vertical axis (which changes the glancing angle $\theta$ ) is produced with the help of a micrometer, which moves a long radial arm of the diffractometer. The specimen can be rotated in steps of 0.5 " The diffracted X-ray intensity is measured by a scintillation counter. Its output is measured by the counting system incorporated in the microprocessor control unit. The detector is mounted with its axis along a radial arm of the turntable. The diffraction data were plotted with Origin 7.0. To analyze the data the deconvolution tool was used which gives the second peak hence the angle separation.

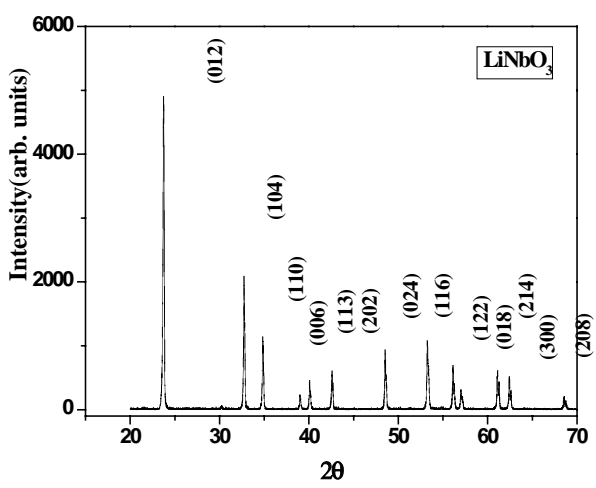

(a)

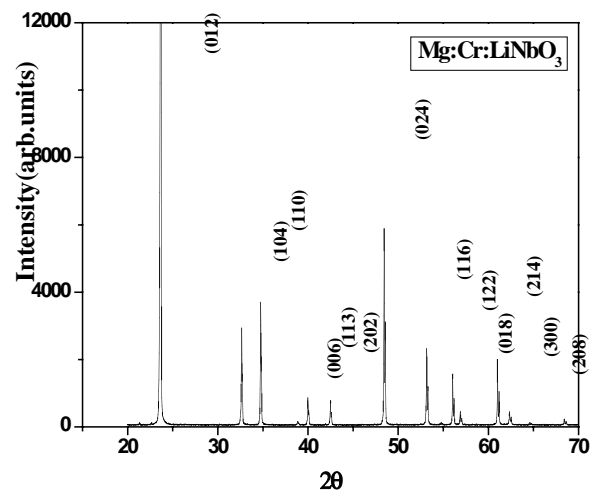

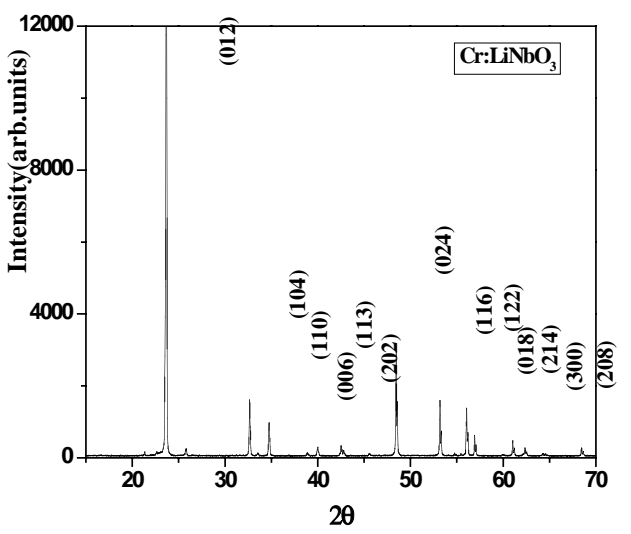

(b)

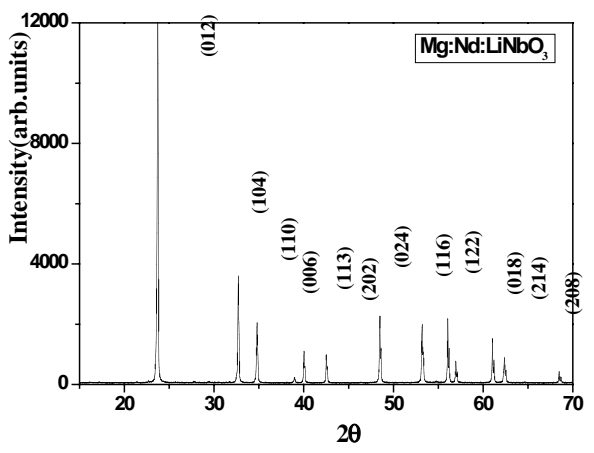

(d)

Fig. (1). XRD patterns for (a) undoped $\mathrm{LiNbO}_{3}$ (b) $\mathrm{Cr}: \mathrm{LiNbO}_{3}$ (c) $\mathrm{Mg}: \mathrm{Cr}: \mathrm{LiNbO}_{3}$ and (d) $\mathrm{Mg}: \mathrm{Nd}: \mathrm{LiNbO}_{3}$ crystals. 


\section{RESULTS AND DISCUSSION}

Transparent, inclusion and crack free single crystals of undoped and doped $\mathrm{LiNbO}_{3}$ with congruent composition were grown successfully by Czochralski technique in air atmosphere. The undoped and $\mathrm{Mg}$ and $\mathrm{Nd}$ doped crystals of $\mathrm{LiNbO}_{3}$ were colorless, whereas the $\mathrm{Cr}$ doped crystals were light green in color. The crystallographic structure of $\mathrm{LiNbO}_{3}$ is rhombohedral with $3 \mathrm{~m}$ point group and $\mathrm{R} 3 \mathrm{c}$ space group correspond to ferroelectric phase. These crystals have a large melting point $1533 \mathrm{~K}$ and undergo a phase transformation at $1483 \mathrm{~K}$ from a hexagonal to rhombohedral structure which is accompanied by a large volume change. $\mathrm{Nb}$ atoms occupy $(0,0,0)$ positions, $\mathrm{Li}$ atoms occupy $(0,0,1 / 4)$ positions and $\mathrm{O}$ atoms occupy $(4,1 / 3,1 / 2)$ positions. The unit cell dimensions for hexagonal lattice are: $\mathrm{a}=5.1494 \mathrm{~A}$ and $\mathrm{c}=13.8620 \mathrm{~A}$.

A small portion of each grown crystal was fine crushed for powder XRD analysis. Fig. (1a,b,c,d) shows the XRD patterns for the undoped and doped $\mathrm{LiNbO}_{3}$ samples. XRD patterns indicate that there is no significant change in the basic lattice of the parent $\mathrm{LiNbO}_{3}$ crystal due to doping. It is understood as the doping level is very small and under the detection limits of the bulk powder XRD technique. The small change in overall intensity is not because of the doping effect it is rather due to the variation in sample particle sizes and batch preparation.

High-resolution X-ray diffractometry (HRXRD) and topography are powerful techniques for structural characterization and have been extensively employed to evaluate crystalline perfection of semiconducting and optical single crystals [17]. These techniques are useful for direct observation of defects and provide valuable feed back for improving structural perfection of the crystals. There are very few studies on structural characterization by these techniques on ferroelectric single crystals. However, such studies are very essential for these crystals because just after the growth during cooling cycle, these crystals generally undergo structural phase transformations accompanied by large volume changes, which lead to crystal defects, like dislocations and grain boundaries. Post growth thermal annealing for longer duration with slow raising and cooling rates was found to be very efficient both in semiconducting and optical crystals. Fig. (2) shows a schematic line diagram of the multicrystal x-ray diffractometer developed and fabricated at NPL [17], employed in the present investigations for high resolution XRD. The specimen occupies the fourth crystal stage and is oriented for diffraction in $(+,-,-,+)$ configuration. This arrangement improves the spectral purity $\left(\Delta \lambda / \lambda<10^{-5}\right)$ of the $M o K \alpha_{1}$ beam. Such an arrangement disperses the divergent part of the $M o K \alpha_{1}$ beam away from the Bragg diffraction peak and there by gives a good collimated and monochromatic $\mathrm{MoK}_{1}$ beam at the Bragg diffraction angle. The height of the x-ray beam can be adjustable which $\sim 6 \mathrm{~mm}$ is at the specimen stage with vertical divergence of $\sim 10$ arc min in these experiments. The divergence of the exploring beam in the horizontal plane (plane of diffraction) was estimated to be $<<3$ arc sec.

Diffraction curves (DCs) were recorded for all the compositions in the same $(+,-,-,+)$ configuration. Fig. $(3 \mathbf{3 a}, \mathbf{b}, \mathbf{c})$ shows the diffraction curves (DCs) for three different compositions. Fig (3a) shows the DC for undoped $\mathrm{LiNbO}_{3}$ crys- tal. From the DC it is clear that it contains one well-resolved peak in addition to the main peak corresponding to low angle ( $\geq 1$ arc min) grain boundary. The additional peak is at 95 arc sec towards higher diffraction angle from the main peak. The full-width at half maximum (FWHM) of the main peak is 20 arc sec, while the peak intensity was measured 550 $\mathrm{c} / \mathrm{sec}$. It may be mentioned here that the additional peak in the observed DC cannot be due to the ferroelectric domain boundaries.

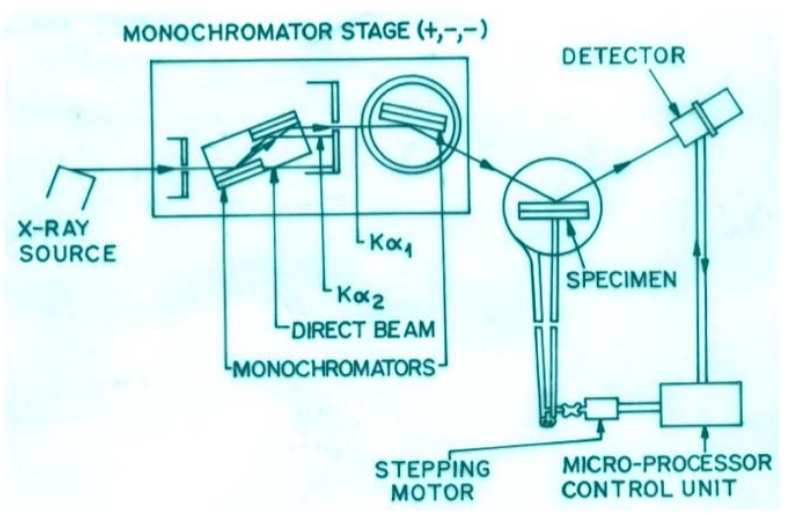

Fig. (2). Schematic diagram of multicrystal X-ray diffractometer developed at NPL Delhi [17].

In ferroelectric domains, only the orientation of dipoles in the adjacent domains is different, which does not change the orientation of lattice planes. However, ferroelectric domain boundaries can contribute diffuse scattering, which may broaden the diffraction curve. To remove or reduce such grain boundaries and to enhance the crystalline perfection of the crystal, post growth thermal annealing with slow heating or cooling for longer time period was found to be very effective [18]. Fig. (3b) shows the DC of $0.5 \mathrm{~mol} \% \mathrm{Cr}$ doped $\mathrm{LiNbO}_{3}$ crystal. The deconvolution of this curve indicates that the experimental DC consists of two curves (dotted line) with an angular separation of 14 arc sec. The FWHM recorded for the main peak is found to be 40 arc sec while the peak intensity is $1075 \mathrm{c} / \mathrm{sec}$. In Fig. (3c) we have shown the DC for the composition $7 \mathrm{~mol} \% \mathrm{Mg}, 0.5 \mathrm{~mol} \% \mathrm{Cr}$ co-doped $\mathrm{LiNbO}_{3}$ crystal. This figure clearly shows that there is only single peak in this crystal. The half width and peak intensity of this peak are $63 \mathrm{arcsec}$ and $1473 \mathrm{c} / \mathrm{sec}$, respectively.

From the DCs of all the grown crystals, it is clear that the crystalline perfection of the $\mathrm{Cr}$ doped and $\mathrm{Mg}, \mathrm{Cr}$ co-doped $\mathrm{LiNbO}_{3}$ crystals is better than the pure $\mathrm{LiNbO}_{3}$ crystal. Since in un-doped $\mathrm{LiNbO}_{3}$, the antisite defects are more prominent, which are being filled by the dopants. This filling up of vacancies makes the crystal more perfect on doping.

Fig. (4a,b) shows the DCs for the $\mathrm{Mg}$ doped and $\mathrm{Mg}$ : $\mathrm{Nd}$ co-doped $\mathrm{LiNbO}_{3}$ crystals. Fig. (4a) is the DC for $7 \mathrm{~mol} \%$ $\mathrm{Mg}$ doped $\mathrm{LiNbO}_{3}$ crystal. The deconvolution of this curve indicates that the DC consists of two curves (dotted line) with an angular separation of 12 arc sec. The FWHM recorded of the main peak is found to be 24 arc sec while the peak intensity is $575 \mathrm{c} / \mathrm{sec}$. Fig (4b) shows the DC for the composition $7 \mathrm{~mol} \% \mathrm{Mg}$, and $1 \mathrm{~mol} \% \mathrm{Nd}$ co-doped $\mathrm{LiNbO}_{3}$ crystal. This figure clearly shows that there is single diffraction peak in the DC. The half width and peak intensity of this peak are 19 arc sec and $1145 \mathrm{c} / \mathrm{sec}$, respectively. Nearly full height of the DC, which is approximately equal to the height 


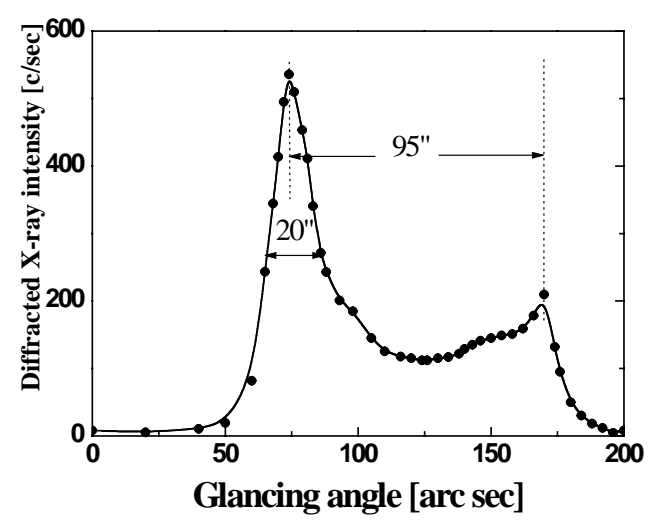

(a)

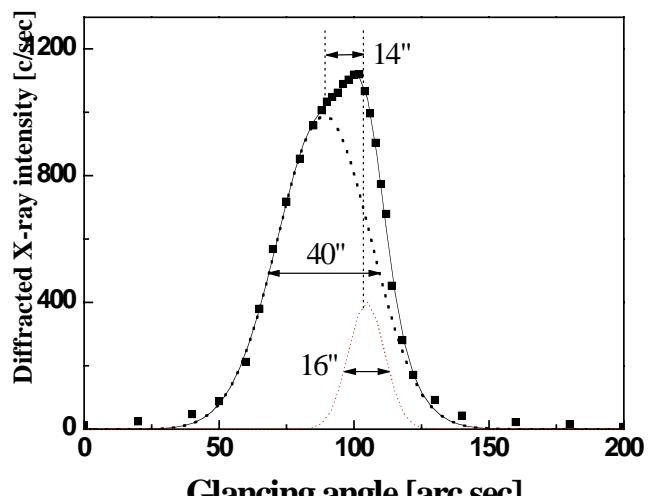

Glancing angle [arc sec]

(b)

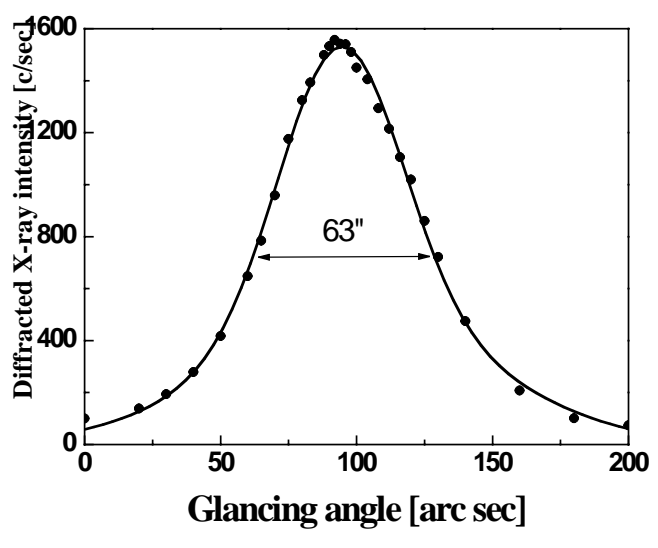

(c)

Fig. (3). High Resolution X-ray diffraction curves recorded for (006) diffracting planes for (a) undoped $\mathrm{LiNbO}_{3}(\mathbf{b}) 0.5 \mathrm{~mol} \% \mathrm{Cr} \mathrm{LiNbO}_{3}$ and (c) $7 \mathrm{~mol} \% \mathrm{Mg}: 0.5 \mathrm{~mol} \% \mathrm{Cr}: \mathrm{LiNbO}_{3}$ crystals.

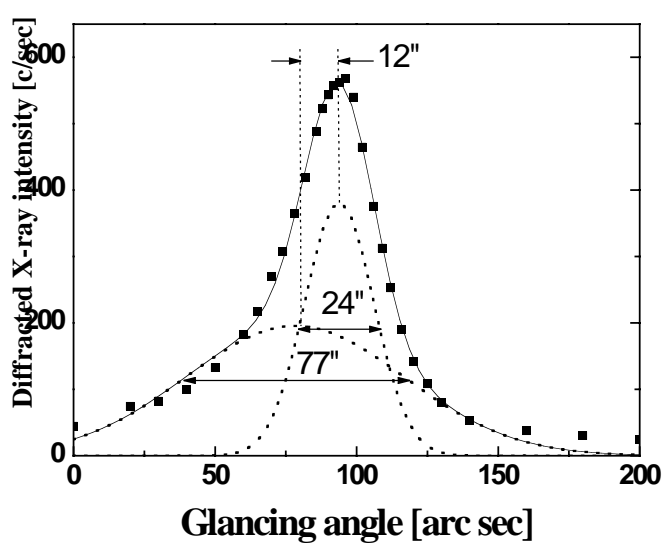

Glancing angle [arc sec]

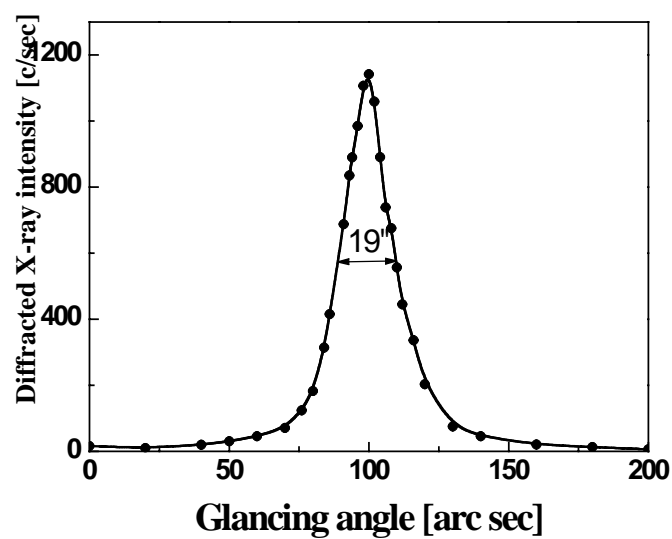

(a) (b)

Fig. (4). High resolution X-ray diffraction curves recorded for (006) diffracting planes for (a) $7 \mathrm{~mol} \% \mathrm{Mg}$ : $\mathrm{LiNbO}_{3}$ and (b) $7 \mathrm{~mol} \% \mathrm{Mg}$ : 1 mol\% $\mathrm{Nd}: \mathrm{LiNbO}_{3}$ crystals.

of the exploring X-ray beam, reveals that the specimen does not contain any structural boundaries. This DC also indicate that crystalline perfection of $\mathrm{Nd}: \mathrm{Mg}: \mathrm{LiNbO}_{3}$ is better than both undoped and $\mathrm{Mg}$ doped $\mathrm{LiNbO}_{3}$ crystals. The doped ions of $\mathrm{Mg}^{2+}, \mathrm{Cr}^{3+}$ and $\mathrm{Nd}^{3+}$ ions are assumed to preferably occupy $\mathrm{Li}$ sites and replace antisite $\mathrm{Nb}_{\mathrm{Li}}$ up to a threshold concentration in $\mathrm{LiNbO}_{3}$ crystal. As the $\mathrm{Mg}$ concentration exceeds the threshold, antisite defects $\mathrm{Nb}_{\mathrm{Li}}$ disappear, while 
$\mathrm{Mg}^{2+}$ separately enters $\mathrm{Nb}$ and $\mathrm{Li}$ sites. In our experiments, the $\mathrm{Mg}$ content in $\mathrm{LiNbO}_{3}: 7 \mathrm{~mol} \% \mathrm{Mg}, 0.5 \mathrm{~mol} \% \mathrm{Cr}$ is sufficient to push all $\mathrm{Nb}_{\mathrm{Li}}$ Similarly in the case of $\mathrm{Mg}: \mathrm{Nd}$ codoped $\mathrm{LiNbO}_{3}$ crystals the overall Li vacancies are filled, which results in higher crystalline perfection.

\section{CONCLUSIONS}

Transparent and crack free crystals of undoped, $\mathrm{Cr}$ doped, $\mathrm{Mg}: \mathrm{Cr}$ co-doped, and $\mathrm{Mg}: \mathrm{Nd}$ co-doped $\mathrm{LiNbO}_{3}$ single crystals were grown successfully. Powder XRD results show that the grown crystals were single phase retaining the parent rhombohedral crystal symmetry. The crystalline perfection of the as grown crystals was monitored using HRXRD technique. The DC for undoped $\mathrm{LiNbO}_{3}$ suggests the presence of low angle grain boundary in the crystal. However, in case of $\mathrm{Cr}$ doped, $\mathrm{Mg}: \mathrm{Cr}$ co-doped, and $\mathrm{Mg}: \mathrm{Nd}$ co-doped $\mathrm{LiNbO}_{3}$ crystals, the crystalline perfection is better compared to the undoped crystal. The better crystallinity in the doped and co-doped crystals is due the filling of Li vacancy sites by doped ions, which results in the overall reduction in Li vacancies.

\section{ACKNOWLEDGMENTS}

The authors are grateful to Dr. G. Bhagwannarayan (NPL) for providing the facilities for recording the HRXRD curves.

\section{REFERENCES}

[1] Rauber A. Physics and Chemistry of $\mathrm{LiNbO}_{3}$. In: Kaldis E (Ed.), Current Topics in Materials Science, North-Holland, Amsterdam, 1978; Vol. 1: pp. 481-578.

[2] McPherson MS, Ostrovskii I, Breazeale MA. Observation of Acoustical Memory in $\mathrm{LiNbO}_{3}$. Phys Rev Lett 2002; 89: 11550608 .

[3] Tsuboi T, Grinberg M, Kaczmarek SM. Site symmetries of $\mathrm{Cu}^{2+}$ ions in $\mathrm{LiNbO}_{3}$ crystals. J Alloys Comp 2002; 341: 333- 37.
[4] Bartwal KS, Srivastava ON. Short- and Long- Range Order of Vacancies in $\mathrm{ZrS}_{2}$ Crystals. Phil Mag B 1993; 67: 277-81.

[5] Bartwal KS. Ti - Atom Disorder in $\mathrm{Ti}_{1+\mathrm{x}} \mathrm{S}_{2}$ Crystals. Phil Mag B 1995; 71: 895-99.

[6] Kityk IV, Janusik MM, Fontana MD, Allerie M, Abdi F. Band structure treatment of the influence of nonstoichiometric defects on optical properties in $\mathrm{LiNbO}_{3}$. J Appl Phys 2001; 90: 5542-47.

[7] Kityk IV, Janusik MM, Fontana MD, Allerie M, Abdi F. Influence of Non-Stoichiometric Defects on Optical Properties in $\mathrm{LiNbO}_{3}$. Cryst Res Technol 2001; 36: 577-81.

[8] Qiu Y. Assessment of the tunable laser crystal $\mathrm{LiNbO}_{3}: \mathrm{Cr}^{3+}$. J Phys Condens Matter 1993; 5: 2041-44.

[9] Malovichko G, Grachev V, Kokanyan E, Schirmer O. Axial and low-symmetry centers of trivalent impurities in lithium niobate: Chromium in congruent and stoichiometric crystals. Phys Rev B 1999; 59: 9113-25.

[10] Capmany J, Jaque D, Sanz Garcìa JA, Garcìa Solé. Continuous wave laser radiation and self-frequency-doubling in $\mathrm{ZnO}$ doped $\mathrm{LiNbO}_{3}: \mathrm{Nd}^{3+}$. Opt Commun 1999; 161: 253-56.

[11] Fan TY, Cordova-Plaza A, Digonnet MJF, Byer RL, Shaw HJ. $\mathrm{Nd}: \mathrm{MgO}: \mathrm{LiNbO}_{3}$ spectroscopy and laser devices. J Opt Soc Am 1986; 3: 140-48.

[12] Choubey RK, Sen P, Sen PK, et al. Optical properties MgO doped $\mathrm{LiNbO}_{3}$ single crystals. Opt Mats 2006; 28: 467-72.

[13] Volk TR, Pryalkin VI, Rubinina NM. Optical-damage-resistant $\mathrm{LiNbO}_{3}: \mathrm{Zn}$ crystal. Opt Lett 1990; 15 (18): 996-98.

[14] Kong Y, Wen J, Wang H. New doped lithium niobate crystal with high resistance to photorefraction- $\mathrm{LiNbO}_{3}$ : In. Appl Phys Letts 1995; 66: 280-81.

[15] Yamanoto JK, Kitamura K, Iyi N, Kimura S, Furukawa Y, Sato M Increased optical damage resistance in $\mathrm{Sc}_{2} \mathrm{O}_{3}$-doped $\mathrm{LiNbO}_{3}$. Appl Phys Letts 1992; 61: 2156-58.

[16] Kar S, Bhatt R, Bartwal KS, Wadhawan VK. Optimisation of chromium doping in $\mathrm{LiNbO}_{3}$ single crystals. Cryst Res Technol 2004; 39: 230- 34 .

[17] Lal K, Bhagvannarayana G. A high-resolution diffuse X-ray scattering study of defects in dislocation-free silicon crystals grown by the float-zone method and comparison with Czochralski-grown crystals. J Appl Cryst 1989; 22: 209-15.

[18] Bhagavannarayana G, Ananthamurthy RV, Budakoti GC, Kumar B, Bartwal KS. A study of effect of annealing on Fe-doped $\mathrm{LiNbO}_{3}$ by HRXRD,XRT and FTIR. J Appl Cryst 2005; 38: 768-71. 